\title{
In which group of children and adolescents should a family doctor look for metabolic syndrome?
}

\author{
IZABELA MARIA BANAŚA-F, PAWEŁ KRZYSZTOF LEWEK'B, D , PRZEMYSŁAW KARDASA, D
}

The First Department of Family Medicine, Medical University of Lodz

A - Study Design, B - Data Collection, C - Statistical Analysis, D - Data Interpretation, E - Manuscript Preparation, $\mathbf{F}$ - Literature Search, $\mathbf{G}$ - Funds Collection

Summary Background. The asymptomatic course, early genesis, multifactorial onset, and the lack of a single definition of metabolic syndrome in children and adolescents make it difficult to assess its prevalence. Metabolic syndrome developed in childhood increases cardiovascular risk in adulthood.

Objectives. The evaluation of the prevalence of metabolic syndrome based on age, sex, weight and abdominal obesity in a population of children and adolescents in a family doctor's practice.

Material and methods. The study group comprised 325 children and adolescents $\left(177+, 148{ }^{\lambda}\right)$ aged 7,13 and 16 years. Anthropometric measurements (height, weight, waist circumference) were made, along with the determination of blood pressure, fasting glucose and lipid levels. Overweight states and obesity were assessed according to the IOTF criteria. Abdominal obesity and hypertension were evaluated using growth charts appropriate for the age, gender and height of the children of Lodz. Metabolic syndrome was diagnosed based on the NCEP/ATP III criteria.

Results. Metabolic syndrome was diagnosed in $6.5 \%$ of the subjects. In children aged 13 and 16 years $-7.6 \%(p>0.05$ vs. 7 years), aged 7 years $-3.9 \%$ ( $p>0.05$ vs. 13,16 years), boys $(8.8 \% ; p>0.05)$, girls $(4.5 \% ; p>0.05)$. Among children with excessive body weight, metabolic syndrome was observed in every fourth child $(25.4 \%)$, more often in those with obesity $(44.1 \%)$ than with abdominal obesity $(32 \%)$ and those who were overweight $(19.2 \%)$, respectively $(p<0.001 v s$. metabolic syndrome). The number of components of metabolic syndrome elevated with increasing body weight $(p<0.001)$. Abdominal obesity was observed in $17.5 \%$ of the subjects. Children with abdominal obesity had higher levels of triglycerides $(p<0.05)$ and lower HDL cholesterol $(p<0.001)$. The most common cardiovascular risk factors were LDL-c > $110 \mathrm{mg} / \mathrm{dl}$ in $85(26.1 \%)$ and excessive body weight in 71 subjects $(21.8 \%)$.

Conclusions. The presence of metabolic syndrome correlated with overweight state, obesity and abdominal obesity in the group of children and adolescents. The evaluation of cardiovascular risk performed in obese children by a family doctor allows for the early implementation of prevention.

Key words: metabolic syndrome, abdominal obesity, obesity, children.

Fam Med Prim Care Rev 2016; 18(3): 217-220

\section{Background}

Even though the relationship between metabolic syndrome in children and adolescents and the threat of adulthood cardiovascular diseases, diabetes and atherosclerosis has been confirmed in clinical studies, the diagnosis is still a challenge for many doctors. Published epidemiological data show that there is a threefold increase in the number of cardiovascular complications and a twofold rise in the associated mortality rate in adults with metabolic syndrome compared to healthy subjects. The risk of developing diabetes in adults with metabolic syndrome increases fivefold [1]. The difficulties in diagnosing metabolic syndrome in children are due to the lack of clearly defined criteria and definitions of metabolic syndrome in this group of patients. In children and adolescents researchers have to use criteria adapted from the terminology of adults, but results vary depending on the definition used. In 2009 the American Heart Association published a stand dedicated to the problem of metabolic syndrome in children and adolescents, but a clear definition of the syndrome was still not given. It was noted that regardless of the definition, the incidence of metabolic syndrome in children and adolescents has increased significantly in recent years, similarly to the incidence of obesity and overweight states in children and adolescents [2]. The definition, based on the NCEP/ATP III criteria adapted for children and adolescents, is commonly used to diagnose metabolic syndrome in adolescents. According to this definition, it is necessary to find 3 out of the 5 following risk factors: abdominal obesity - waist circumference $\geq 90$ percentile for age and sex, plasma glucose concentration $\geq 110 \mathrm{mg} /$ $/ \mathrm{dl}$, triglyceride levels $\geq 110 \mathrm{mg} / \mathrm{dl}$, HDL-cholesterol in plas$\mathrm{ma} \leq 40 \mathrm{mg} / \mathrm{dl}$, arteriovenous pressure $\geq 90$ percentile for sex, age and height [3]. Metabolic syndrome and cardiovascular diseases may begin in early childhood, and are usually asymptomatic. The theory of the perinatal programming of these diseases, which is described by researchers, indicates the need for the early identification of at risk groups. The first symptoms of metabolic syndrome can be manifested as early as in the first decade of life [4]. Early diagnosis should therefore be addressed to the group of children and adolescents who are at highest risk of metabolic syndrome.

\section{Objectives}

The aim of this study was to evaluate the prevalence of metabolic syndrome and its components in a population of children and adolescents, by a family doctor, depending on age, sex, body weight and abdominal obesity. 


\section{Material and methods}

The study comprised 325 children $(177 q, 148 \hat{)})$ aged 7, 13 and 16 years from the three largest age groups who were recruited for the study during visits to the outpatient clinic. Anthropometric measurements were made. Overweight states and obesity were assessed based on the IOTF criteria (International Obesity Task Force) as an international standard for comparison of the results [5]. Abdominal obesity was diagnosed as waist circumference above percentile 90 on growth charts appropriate for the children of Lodz; blood pressure was evaluated based on growth charts appropriate for age, sex, and height also for the children of Lodz [6]. Blood glucose and lipid profile were determined in venous blood on an empty stomach. Metabolic syndrome was diagnosed as defined by NCEP/ATP III (National Cholesterol Education Program Adult Treatment Panel III) [3].

\section{Results}

According to the accepted NCEP/ATP III definition, metabolic syndrome was diagnosed in $6.5 \%$ of patients, with 3 out of 5 cardiovascular risk factors included in the syndrome definition: abdominal obesity, elevated TG level, low HDL-c concentration, increased glucose value, and abnormal blood pressure. Metabolic syndrome is most commonly diagnosed among subjects aged $13(7.6 \%)$ and 16 years $(7.6 \%)$, and less frequently in the group of the youngest children, i.e. at the age of 7 years $(3.9 \%)$. There was no significant relationship between gender, age and the prevalence of metabolic syndrome. Despite the differences that exist in metabolic syndrome prevalence in various age groups, there was no statistically significant difference in this respect $(p>0.05)$. There are also no relationships between the groups with metabolic syndrome and gender, although the prevalence in boys $(8.8 \% ; p>0.05)$ is higher than in girls $(4.5 \% ; p>0.05)$. The group of children with a diagnosis of metabolic syndrome showed a relationship between excessive body weight and the disease $(p<0.001)$. Metabolic syndrome was diagnosed in almost every fifth overweight child (19\%) and in almost half of obese children (44\%). In total, in the whole group of overweight and obese children (71), 18 subjects presented the characteristics of metabolic syndrome $(25.4 \%)$. In the group of normal weight and underweight children, metabolic syndrome occurred in every hundredth subject. In the group of children with abdominal obesity, metabolic syndrome was determined in every third subject $(32 \%)$, while in those without abdominal obesity in only $2 \%$, regardless of age and gender $(p<0.001)$. The assessment of the presence of metabolic syndrome components depending on body weight revealed that the number of components increased with growing body weight $(p<0.001)$. All the obese children demonstrated the components of metabolic syndrome; every third obese child presented three components, which was the basis for the diagnosis of metabolic syndrome. Children with abdominal obesity had higher triglyceride levels $(165 \pm 62.9 ; 95 \% \mathrm{Cl}$ : $29.3-23.6 ; p<0.05)$ and lower $\mathrm{HDL}(41.9 \pm 8.0 ; 95 \% \mathrm{Cl}$ : $5,99-47 ; p<0.001)$ compared to children without obesity. In the study group, cardiovascular risk factors most frequently included elevated levels of LDL-c > $110 \mathrm{mg} / \mathrm{dl}$ (according to the recommendation of the Polish Forum of Cardiovascular Prevention for Children and Youth), present in 85 (26.1\%), and excessive body weight in 71 subjects (21.8\%) [7].

\section{Discussion}

According to the assumed definition, metabolic syndrome was diagnosed in $6.5 \%$ of all subjects aged $7-16$ years. The published study results, which used the NCEP/ /ATP III definition, showed that the prevalence of metabolic syndrome in children aged 10-18 years ranged from $4.2 \%$ to $15.4 \%$ [8]. A high percentage of children with metabolic syndrome according to the same criteria (NCEP/ATP III) was observed in studies conducted in Arab children, 9.4\% and $10.8 \%$, respectively $[9,10]$. A higher prevalence of metabolic syndrome, i.e. $8.6 \%$ of children compared to the results of our study $(6.5 \%)$ was reported in a multicentre study of American children in the National Health and Nutrition Examination Survey (NHANES) in the years 2001-2006 [11]. The studies, which found a higher percentage of children with metabolic syndrome, involved children of different races and ethnic backgrounds, as well as a higher percentage of obese Latino children, which significantly increased the prevalence of metabolic syndrome [11]. A recently published study conducted by Piotrowska et al. among the adolescents of Wroclaw showed abdominal obesity as part of metabolic syndrome in $34.5 \%$ of 17 -year-olds and in $65.5 \%$ of 18-year-olds [12]. The study results showed that metabolic syndrome in children and adolescents was a complex diagnostic problem due to ethnic differences, the child $/ s$ development, and changes in anthropometric parameters. In European studies the prevalence of metabolic syndrome in Hungarian children aged $8-18$ years was $8.9 \%$, and $4 \%$ in Finnish children aged 6-18 years. The difference is due to environmental conditions, high-calorie and protein-rich diets, and a predominance of sedentary lifestyle, as seen in developing countries compared to developed countries [13]. The studies mentioned above found no statistically significant correlation between gender and the prevalence of metabolic syndrome. Similar findings were obtained in our study. Although metabolic syndrome was more frequent in boys, the difference was statistically insignificant $(p>0.05)$.

The prevalence of metabolic syndrome in the analyzed group of children and adolescents with excessive body weight was $25.4 \%(n=71)$, that is 18 subjects. Metabolic syndrome was diagnosed in $44 \%$ of obese children and $19 \%$ of overweight subjects. The frequency of metabolic syndrome diagnosis in children with excessive body weight was significantly increased compared with children with normal body weight $(p<0.001)$. The study adapted the international IOTF standard to assess obesity and overweight states. BMI values were determined for each age group of boys and girls in such a way that BMI $=25 \mathrm{~kg} / \mathrm{m}^{2}$ (overweight) and $\mathrm{BMI}=30 \mathrm{~kg} / \mathrm{m}^{2}$ (obesity) are reached the age of 18 years [5]. In the case of the Polish growth charts used in our study and developed in the OLAF study (in 18-year-olds BMI percentile runs through $\mathrm{BMI}=25 \mathrm{~kg} / \mathrm{m}^{2}$ ), percentile 85 (actually 82.9 ) related to boys and percentile 90 (actually 90.5) to girls. For these reasons, the IOTF definitions were used in this study to determine the prevalence of obesity and overweight states. The criteria created by the Mother and Child Institute, and growth charts developed in the OLAF study are the gold standard in everyday practice [14].

In the literature, the prevalence of metabolic syndrome in overweight children varies depending on the adapted definition, from $19.2 \%$ to $52.9 \%$ [15]. The results of the study conducted among obese children by Bokor et al. and published in 2008 in five European countries: France, Greece, Italy, Hungary and Poland, found the prevalence of metabolic syndrome to be $20.3 \%$ according to the NCEP/ATP III criteria [16]. The prevalence of metabolic syndrome in the studies carried out among the children of Lodz with excessive body weight was $32 \%$. Similarly, in our study, metabolic syndrome or two of its components were more often diagnosed in obese children than in overweight children [17]. Carbohydrate disorders, such as impaired fasting glucose, favour the development of insulin resistance in obese children, in whom metabolic syndrome was diagnosed in 
$12.8 \%$ of cases [18]. A study of 500 Polish children with type 1 diabetes reported that metabolic syndrome occurred in $3.2 \%$ of them, and almost $1 / 3$ of subjects presented features of obesity/overweight state [19]. In turn, a study of 163 children in Lodz with type 1 diabetes found abdominal obesity in $11.7 \%$ and metabolic syndrome in $7.4 \%$ of patients [20]. In a study of obese children Polish, 17 out of 84 met the metabolic syndrome criteria. Abdominal obesity, lipid disorders and hypertension contributed to the development of atherosclerosis, as confirmed by the measurement of intima-media thickness (IMT) of the carotid artery in obese Polish children [21]. Obesity, particularly abdominal, is directly clinically and epidemiologically associated with the development of metabolic syndrome.

The measurement of waist circumference is a simple research tool used in everyday practice to assess abdominal obesity. Gender-specific fixed limits of waist circumference have been established in adults, above which the cardiometabolic risk increases [1]. Because anthropometric parameters change with age, the limit value of waist circumference in children and adolescents was percentile 90. The possibility of using valid growth charts which are appropriate in environmental, ethnical and racial terms, is extremely important to define obesity in children and adolescents, as a leading cardiometabolic risk factor associated with insulin resistance. Because of the practical use of the metabolic syndrome definition in daily work, the determination of insulin resistance was replaced with an accurate and simple measurement of waist circumference and the assessment of abdominal obesity as an intermediate exponent of insulin resistance [22]. In the study group of children and adolescents, the prevalence of metabolic syndrome was significantly higher in patients with abdominal obesity $(p<0.01)$. Features of metabolic syndrome were present in every third child with abdominal obesity $(31.5 \%)$ and in only every fiftieth child without abdominal obesity (2\%). A study of obese children in Wroclaw found three or more components of metabolic syndrome in $50 \%$ of children with abdominal obesity. The analysis of the prevalence of metabolic syndrome components in children with peripheral and abdominal obesity revealed that metabolic syndrome was significantly more frequent in the subgroup with an abdominal accumulation of fat [23]. The study of 63515 -yearolds conducted by Bitsori et al. reported the prevalence of metabolic syndrome in children with abdominal obesity at $13.5 \%$. The published study results indicate abdominal obesity as a leading factor associated with insulin resistance and metabolic syndrome in children and adolescents [24].
The measurement of waist circumference in children and adolescents, which is easy to apply in practice and independent of BMI in the assessment of cardiovascular risk, can be used for routine balance measurements.

Abdominal obesity is also a good predictor of future insulin resistance, dyslipidemia and hypertension [25]. Metabolic syndrome in children is not only described as a cardiovascular risk factor, but also as a chronic kidney disease risk factor. Hypertension and diabetic nephropathy are pathophysiologically associated with insulin resistance and abdominal obesity. Having their origin in childhood, they may increase the risk of chronic kidney disease complications in adulthood [26].

In summary, family doctors should implement educational activities for children diagnosed with metabolic syndrome, and their parents, on proper nutrition and the role of physical activity and leisure time in order to avoid the development of obesity and overweight states, including abdominal obesity, in the future. Children with lipid metabolism disorders and obesity should be referred to the outpatient clinic of metabolic disorders and a nutritionist, as well as undergo the control of lipid parameters. Actions directed to children and young people at cardiovascular risk should occur on many levels, both in the microenvironment (home, family, school) and on a larger scale (health care system, television, advertising, food industry). Metabolic syndrome and obesity in children and adolescents is not just a health problem. It can cause serious economic, psychological and social consequences in the future, in adulthood.

\section{Conclusions}

Children and adolescents with excessive body weight, obesity and associated lipid disorders are at the highest risk of developing metabolic syndrome among the patients of family doctors. In children and adolescents the diagnosis of metabolic syndrome correlated with the presence of overweight states, obesity and abdominal obesity. The disturbingly high percentage of subjects with these disorders indicate the need to take preventive measures in this group of children. Routine measurements of waist circumference and biochemical parameters of cardiometabolic risk should be considered in children with excessive body weight. A change in eating habits, increasing physical activity, and the control of biochemical abnormalities are the areas of prevention activities which should be implemented by family doctors among children at risk of metabolic syndrome.

Source of funding: This work was funded under 2.6. Regional Innovation Strategies and Knowledge Transfer Project no. Z/2.10/ II/2.6/1/.09.

Conflict of interest: The authors declare no conflict of interests.

\section{References}

1. Zimmet P, Alberti KG, Kaufman F, et al. The metabolic syndrome in children and adolescents - an IDF consensus report. Pediatr Diabetes 2007; 8(5): 299-306.

2. Steinberg J, Daniels SR, Eckel RH, et al. Progress and challenges in metabolic syndrome in children and adolescents: a scientific statement from the American Heart Association Atherosclerosis, Hypertension, and Obesity in the Young Committee of the Council on Cardiovascular Disease in the Young; Council on Cardiovascular Nursing; and Council on Nutrition, Physical Activity, and Metabolism. Circulation 2009; 119(4): 628-647.

3. Executive Summary of the Third Report of the National Cholesterol Education Program (NCEP) Expert Panel on Detection, Evaluation, and Treatment of High Blood Cholesterol in Adults (Adult Treatment III). JAMA 2001; 285(19): 2486-2497.

4. Szałapska M, Stawerska R, Borowiec M, et al. Cechy zespołu metabolicznego obserwowane w pierwszej dekadzie życia u dzieci urodzonych ze zbyt niską masą ciała. Pediatr Endocrinol 2010; 16(4): 270-276.

5. Cole TJ, Bellizzi MC, Flegel KM, et al. Establishing a standard definition for child overweight and obesity worldwide: international survey. BMJ 2000; 320: 1240-1243.

6. Ostrowska-Nawarycz L. Percentile distributions of waist circumference for 7-19-year-old Polish children and adolescents. Obes Rev 2010; 1(4): 81-288. 
7. Podolec P, ed. Podręcznik Polskiego Forum Profilaktyki. T. 2. Kraków: Medycyna Praktyczna; 2010: 603-609.

8. Moraes AC, Fulaz CS, Netto-Oliveira ER, et al. Prevalence of metabolic syndrome in adolescents: a systematic review. Cad Saude Publica 2009; 25(6): 1195-1202.

9. Al-Daghri NM. Extremly high prevalence of metabolic syndrome manifestations among Arab youth: a call for early intervention. Eur J Clin Invest 2010; 40(12): 1063-1066.

10. Barzin M, Hosseinpanah F, Ferki S, et al. Predictive value of body mass index and waist circumference for metabolic syndrome in 6-12 years olds. Acta Paediatr 2011; 100(5): 722-727.

11. Johnson WD, Kroon JM, Greenway Fl, et al. Prevalence of risk factors for metabolic syndrome in adolescents. NHANES 2001-2006. Arch Pediatr Adolesc Med 2009; 163(4): 371-377.

12. Piotrowska E, Broniecka A, Biernat J, et al. Influence of non-dietary factors on the prevalence of abdominal obesity as a major component of the metabolic syndrome among 17-18-year-old youth. Rocz Państ Zakt Hig 2015; 66(1): 85-92.

13. Kelishadi R. Childhood overweight, obesity and the metabolic syndrome in developing country. Epidemiol Rev 2007; 29(1): 62-67.

14. Kułaga Z, Różdżyńska A, Palczewska I, and Group of Researches OLAF. Siatki centylowe wysokości, masy ciała i wskaźnika masy ciała dzieci i młodzieży w Polsce - wyniki badania OLAF. Stand Med, Pediatr 2010; 7: 690-700.

15. Fang QY, Wan YP, Wang Jl, et al. Comparison of different definitions on metabolic syndrome in obese children. Zhonghua Liu Xing Bing Xue, Za Zhi 2009; 30(12): 1297-1301 (Abstract).

16. Bokor S, Freult M-L, Vania A, et al. Prevalence of metabolic syndrome in European obese children. Int J Pediatr Obes 2008; 3(Suppl. 2): 3-8.

17. Kulińska-Szukalska K, Golec J, Ligenza I, et al. Choroby cywilizacyjne w wieku rozwojowym - zespół metaboliczny u dzieci łódzkich w okresie dojrzewania Pediatr Pol 2010; 85(6): 555-560.

18. Zachurzok-Buczyńska A, Klimek K, Firek-Pedras M, et al. Are metabolic syndrome and its components in obese children influenced by the overweight status or the insulin resistance? Endokrynol Pol 2011; 62(2): 102-108.

19. Łuczyński W, Szypowska A, Głowińska-Olszewska B, et al. Overweight, obesity and features of metabolic syndrome in children with diabetes treated with insulin pump therapy. Eur J Pediatr 2011; 170(7): 891-898.

20. Szadkowska A, Pietrzak I, Szlawska J, et al. Abdominal obesity, metabolic syndrome in type 1 diabetic children and adolescents. Pediatr Endocrinol 2009; 15(4): 233-239.

21. Rumińska M, Majcher A, Pyrżak B, et al. Cardiovascular risk factors in obese children and adolescents. Adv Exp Med Biol 2016; 878: 39-47.

22. I'Allemand-Jander D. Clinical diagnosis of metabolic and cardiovascular risks in overweight children: early development of chronic diseases in the obese children. Int J Obes 2010; 34(2): 32-36.

23. Iwanicka Z, Głąb E, Barg E. Zespół metaboliczny u dzieci z otyłością prostą. Wiad Lek 2005; 58(11-12): 602-606.

24. Bitsori $M$, Linardakis $M$, Tabakaki $M$, et al. Waist circumference as a screening tool for the identification of adolescents with metabolic syndrome phenotype. Int J Pediatr Obes 2009; 4(4): 325-331.

25. Szadkowska A. Zespół metaboliczny u dzieci i młodzieży. Aktual Med 2010; 3: 23-29.

26. Litwin M, Niemirska A. Metabolic syndrome in children with chronic kidney disease and after renal transplantation. Pediatr Nephrol 2014; 29(2): 203-216.

Address for correspondence:

Izabela Banaś, MD, PhD

I Zakład Medycyny Rodzinnej UM

ul. Narutowicza 60

Polska

90-136 Łódź

Tel.: +48 42 678-72-10

E-mail: izabela.banas@umed.lodz.pl, ibanas@wp.pl

Received: 30.03.2016

Revised: 21.05.2016

Accepted: 21.05.2016 